\section{White Fiber Dissection of Brain; the Internal Capsule: A Cadaveric Study}

\section{Beyin ve Kapsüla Internanın Beyaz Cevher Diseksiyonu: Kadavra Çalıșması}

\begin{abstract}
AIM: This study was done to study the three dimensional anatomy of internal capsule's white fibers completely by cadaveric dissection and its relation to basal ganglia and other related anatomical structures.

MATERIAL and METHODS: Eight formalin fixed cerebral hemispheres were dissected for internal capsule under operating microscope. Klingler's technique of fiber dissection was adopted. The internal capsule was dissected from superiolateral, inferior and medial surface of cerebral hemisphere. During and after dissection its relation with basal ganglia and other related structures were studied.

RESULTS: The internal capsule was demonstrated by dissecting fibers of all its parts. Fibers that forms the internal capsule originate from different parts of cerebral cortex and pass through corona radiata that lies in lateral periventricular area and lateral to the caudate nucleus above the upper border of lentiform nucleus. The internal capsule is situated medial to lentiform nucleus and lateral to caudate nucleus and thalamus. Caudally it continues in the midbrain as cerebral peduncle. It has an anterior limb, genu, posterior limb, retrolentiform and sublentiform part. The relation of different parts of internal capsule with surrounding structures were also shown.
\end{abstract}

CONCLUSION: Knowledge of the microsurgical anatomy of the internal capsule and other white fibers tracts is essential for neurosurgeons and other neuroscientists.

KEYWORDS: Internal capsule, White fiber dissection, Microsurgical anatomy.

\section{ÖZ}

AMAÇ: İnternal kapsülün beyaz liflerinin 3 boyutlu anatomisi ve bu liflerin basal ganglionlar ve çevre anatomik yapılarla olan ilişkisi kadaverik doku örneklerinde çalışılmıştır.

YÖNTEM ve GEREÇ: Formalinle doku tesbiti yapılmış 8 serebral hemisfer incelenmiştir. Bu hemisferlere ait internal kapsül lifleri operasyon mikroskopu kullanılarak incelenmiştir. Çalışmamızda Klinger'in geliştirmiş olduğu fiber diseksiyon tekniği kullanılmıştır. İnternal kapsül serebral hemisferin inferior lateral bölgesinden süperiora doğru diseke edilmiştir. Diseksiyon sırasında ve sonrasında internal kapsülün basal ganglionlar ve komşu yapılar ile olan ilişkisi incelenmiştir.

BULGULAR: İnternal kapsülün tüm komşulukları yapılan diseksiyon ile gösterilmiştir. İnternal kapsül serebral korteksin değişik bölümlerinden köken alır ve lateral periventriküler alanda yer alan korona radiata ile kaudat nükleus ve lentiform nükleusun üst sınırının arasından geçer. İnternal kapsül lentiform nükleusun medialinde kaudat nükleusun ve talamusun latralinde yer alır. Kaudale doğru mesensephalona iner ve Serebral pedunkul haline gelir. İnternal kapsül 3 kısımdan oluşur; ön bacak, dirsek, arka bacak. İnternal kapsül retrolentiform ve sublentiform bir seyir izler. İnternal kapsülün değişik bölgelerdeki komşuluk ilişkileri de gösterilmiştir.

SONUÇ: İnternal kapsülün ve diğer beyaz lif yollarının mikrocerrahi anatomisinin bilinmesi beyin cerrahları ve sinirbilimciler için esasdır.

ANAHTAR SÖZCÜKLER: Beyaz lif diseksiyonu, İnternal kapsül, Mikrocerrahi anatomi

\section{Forhad CHOWDHURY ${ }^{1}$ \\ Mohammod HAQUE 2 \\ Mainul SARKAR ${ }^{3}$ \\ Shamim ARA 4 \\ Mohammod ISLAM ${ }^{5}$}

1,2,3,5 Dhaka Medical College Hospital, Department of Neurosurgery, Dhaka, Bangladesh

4 Dhaka Medical College, Department of Anatomy, Dhaka, Bangladesh

Received : 17.05.2010

Accepted : 15.06.2010

Correspondence address:

Forhad Hossain CHOWDHURY

Department of Neurosurgery,

Dhaka Medical College Hospital,

32 Bokshibazar, Dhaka-1200, Bangladesh.

Phone : +880171 1949570

Fax : +008 8069163177

E-mail: forhadchowdhury@yahoo.com 


\section{INTRODUCTION}

Though the gross anatomy of the brain has been studied by anatomists and clinicians, the intrinsic 3dimensional microanatomical study of the complex fibers of the white matter is still somewhat neglected. Very few publications regarding this topic are available. Recently in Rhoton's masterpiece, "The Supratentorial Cranial Space: Microsurgical Anatomy and Surgical Approaches" - Supplement of Neurosurgery, some beautiful dissections showing the internal fasciculus can be appreciated (14]. Radiological and micro-neurosurgical techniques become increasingly precise. To continue this microneurosurgical development, knowledge of the 3-dimensional micrcoanatomy of the internal capsule and other white fiber tract of brain is essential for management of various intrinsic neoplastic, vascular and other pathological brain lesions that can produce clinical symptoms and signs by involving the parts of the internal capsule or by pressure over it. In fact, in the studies and management of the intrinsic brain lesion such as the gliomas, the 3-dimensional microanatomy of the white matter tracts is more important than the anatomy of the sulci (8) The knowledge and experience gained from this technique can be applied to micro-neurosurgical procedures. Three dimensional micro-neuroanatomical description of internal capsule will not only help the neurosurgeon but also the neurologist, neuropathologist and the neuroradiologist. This type of cadaveric study is relatively rare in literature.

\section{MATERIAL and METHODS}

Eight cerebral hemispheres that were formalinated ( $10 \%$ formalin) for 3-6 months were taken for dissection of internal capsule in the Department of Neurosurgery, King Edward Memorial Hospital, Parel, Mumbai, India and the Department of Anatomy, Dhaka Medical College, Dhaka, Bangladesh. The formalinated brains were preserved in the refrigerator for 4 weeks before commencement of dissection. The internal capsule was dissected out using Klingler's fiber dissection method under operating microscope. Dissection was done by bamboo made small spatulas with different sized tip, ice cream sticks and surgical dissector.

The dissection started at the supero-lateral surface of the cerebral hemispheres.

\section{Supero-lateral dissection (Figures 1-5) :}

The supero-lateral surface of each cerebral hemisphere is markedly convex and fits into the corresponding half of the skull vault. Under the microscope, the gray mater over superior-lateral surface was removed. U-pattern short association fibers were identified under the gray matter that were dissected out and removed. The insula is an invaginated portion of the cerebral cortex that forms the floor of the lateral sulcus. The insula was opened up by removing the lips bordering the lateral sulcus and its rami. These lips are known as the pars orbitalis, pars triangularis and pars opercularis. After their removal, the insula appears as a triangular eminence that is marked by a number of sulci and gyri (Figure 1). The insular gray matter was removed revealing a number of sulci, one of which the central sulcus of the insula is deep and prominent than the rest. Again the " $U$ " fibers of the insula gyri were visualized as well as the circular sulcus of the insula which surrounds the entire insula except at limen insulae. Thus entire gray matter of the whole cerebral hemisphere was removed revealing the "U" short association fibers of the white matter underneath.

The ' $U$ ' short association fibers of insula and surrounding areas of frontal parietal, occipital and temporal lobe were removed to expose extreme capsule that is a thin sheet of white fibers that lies under the insula and external to claustrum. The claustrum is a thin layer of gray matter exposed by removing extreme capsule. The external capsule, that is a white matter sheet, lies out side the lentiform nucleus (Figure 2). It is thicker and more prominent than the extreme capsule. After dissection and removal of external capsule fibers the lentiform nucleus was exposed. Anterio- inferio- lateral to the lentiform nucleus the U-shaped uncinate fascicle was dissected out that connects frontal and temporal lobe through limen insula. Some fibers from here joins to external capsule and optic radiation; actually these fibers are so called inferior longitudinal fascicle that connects the frontal, parietal and occipital lobe. The anterior end of optic radiation lies just posterior to uncinate fascicle in the roof of temporal horn of lateral ventricle. Then the superior longitudinal fasciculus, the largest of the bundles, located along the upper and lateral border of the lentiform nucleus and insula was dissected out. It arches backward 
from the frontal lobe lateral to the internal capsule and through the parietal to the occipital lobe, where it arches downward and forward to reach the temporal lobe. It interconnects widely frontal, parietal, occipital and temporal lobe by its short and long fibers. Following dissection and removal of superior longitudinal fascicle and lentiform nucleus corona radiata and internal capsule was exposed and dissected out completely including optic radiation up to cerebral peduncle (Figures 3,4,5). Then a portion of internal capsule and adjacent caudate nucleus was removed to open the lateral ventricle; then medial relation of internal capsule was studied (Figure 3).

\section{Inferior surface dissection:}

Lamina terminalis was identified and removed, and then the anterio-inferior portion of hypothalamus (anterior portion of lateral wall of third ventricle) was removed to expose the anterior margin and anterior part of internal capsule. The anterior commissure was identified at the superior attachment of lamina terminalis and dissected laterally up to anterior temporal lobe. Most of the temporal lobe was removed to expose the optic radiation, optic tract and hippocampus (Figures $6,7,8)$.

\section{Medial surface dissection:}

On the medial surface of cerebral hemisphere, the mamillary body was identified and the mamillothalamic tract was dissected out on the

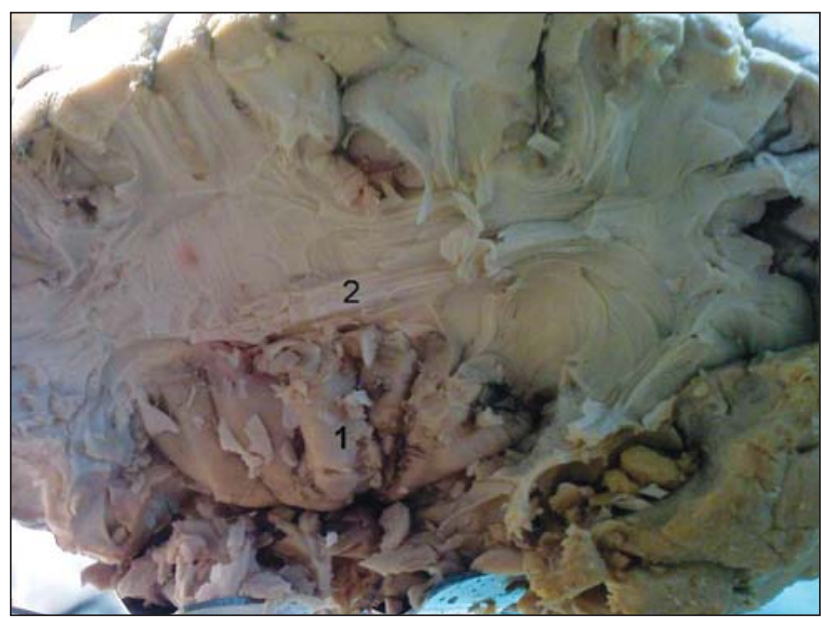

Figure 1: Dissection from lateral surface of left cerebral hemisphere. Operculum are removed to expose insula at the floor of lateral sulcus. 1-insula;2-superior longitudinal fasciculi (partially removed).

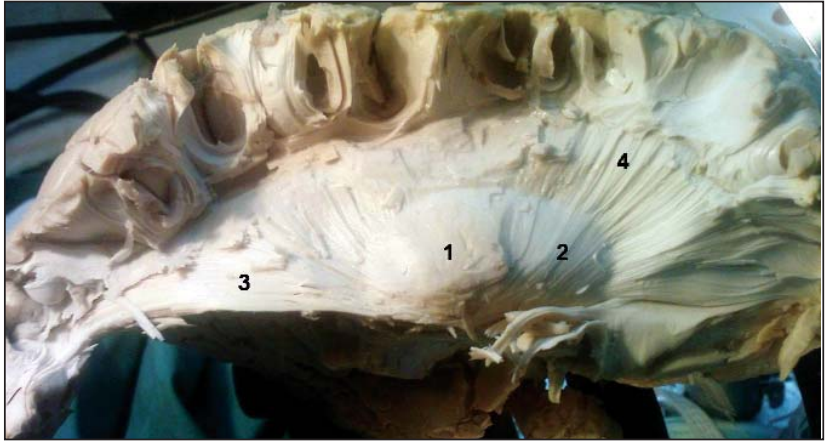

Figure 2: Dissection on the lateral cerebral surface of right cerebral hemisphere (continued), superior longitudinal fascicle, insula, extreme capsule, claustrum and part of external capsule removed. 1-lentiform nucleus, 2-external capsule, 3-optic radiation, 4-corona radiata.

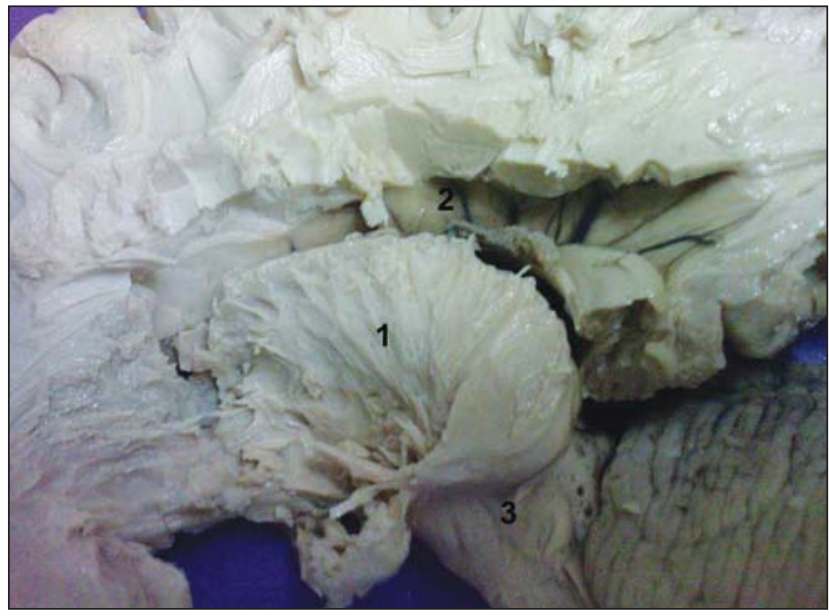

Figure 3: Dissection on lateral surface of left cerebral hemisphere (continued). Lentiform nucleus removed to expose internal capsule (1). Internal capsule (1) continued below with crus cerebri (3). Corona radiate and part of caudate nucleus removed to expose lateral ventricle (2).

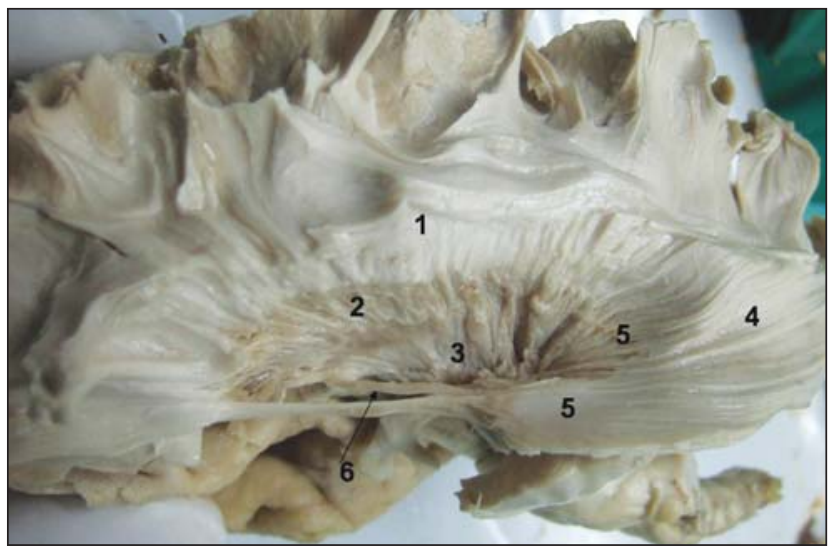

Figure 4: Complete exposure of left Internal capsule from lateral surface. 1-corona radiate, 2, $3 \mathcal{E} 5$ internal capsule(2-area for putaman, 3-area for globus pallidus, 5-retro and sublentiform part of internal capsule), 4-optic radiation, 6-anterior commissure. 


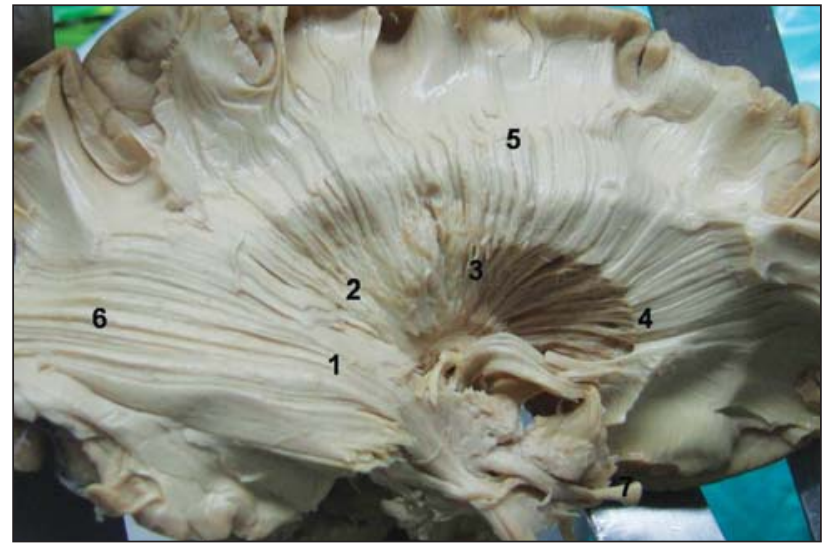

Figure 5: Complete exposure of right internal capsule from lateral surface. 1-retro and sublantiform part of internal capsule, 2-posterior limb, 3-genu, 4-anterior limb of internal capsule,5corona radiate, 6-optic radiation.

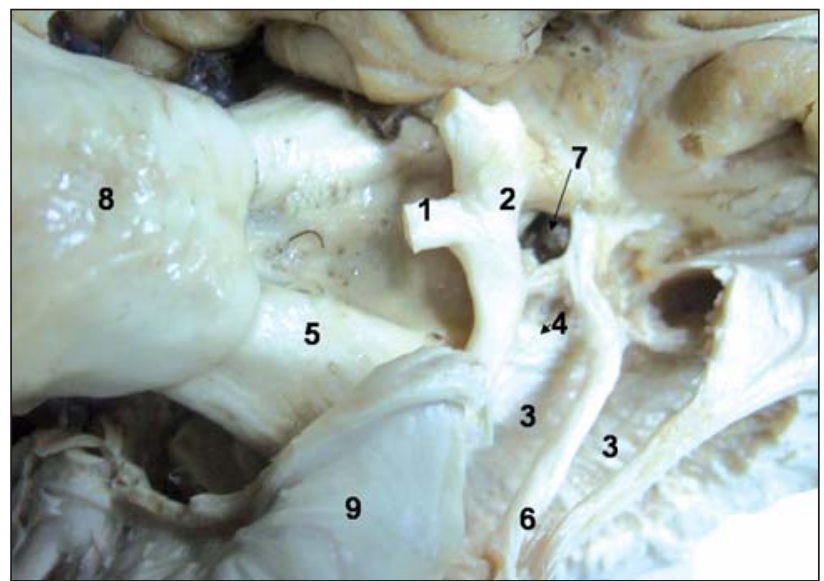

Figure 6: Dissection from inferior cerebral surface to expose anterior border of internal capsule (4). 1-optic nerve, 2-optic chisma, 3-internal capsule, 4-anteror border of internal capsule, 5-crus cerebri, 6-anterior commissure, 7-third ventricle(lamina terminalis open), 8-pons, 9-head of hippocampus.

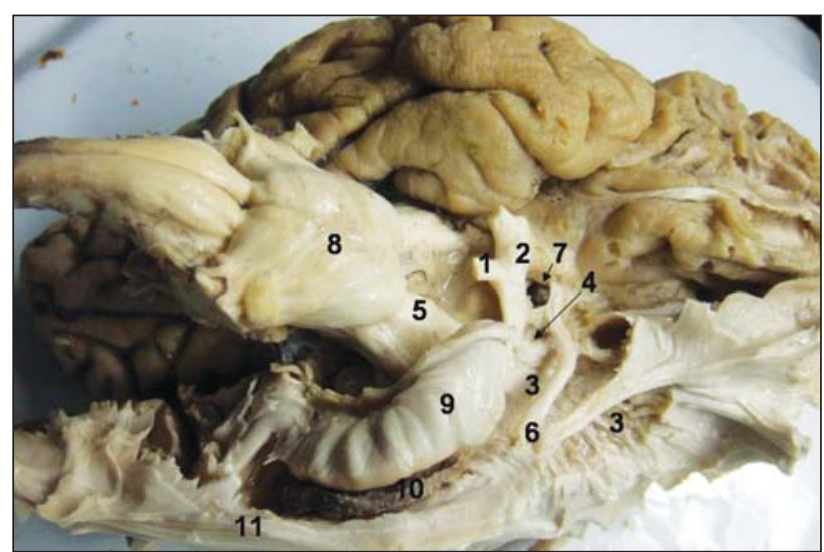

Figure 7: Inferior cerebral dissection to expose left internal capsul. Temporal horn of lateral ventricle is exposed. 1-optic nerve, 2-optic chisma, 3-internal capsule, 4-anteror border of internal capsule, 5-crus cerebri, 6-anterior commissure, 7-third ventricle(lamina terminalis open), 8-pons, 9-head of hippocampus, 10-choroid plexus of temporal horn of lateral ventricle, 11-optic radiation lateral wall of the third ventricle up to the anterior group of thalamic nucleus. The fibers from the anterior thalamic nuclei (anterior thalamic radiation) were dissected out lateral to the head of the caudate nuclei. This anterior thalamic radiation joins the anterior limb of the internal capsule (Figure 9). By removing the body of caudate nucleus, the superior and posterior thalamic radiation that joins the posterior limb of the internal capsule was dissected out.

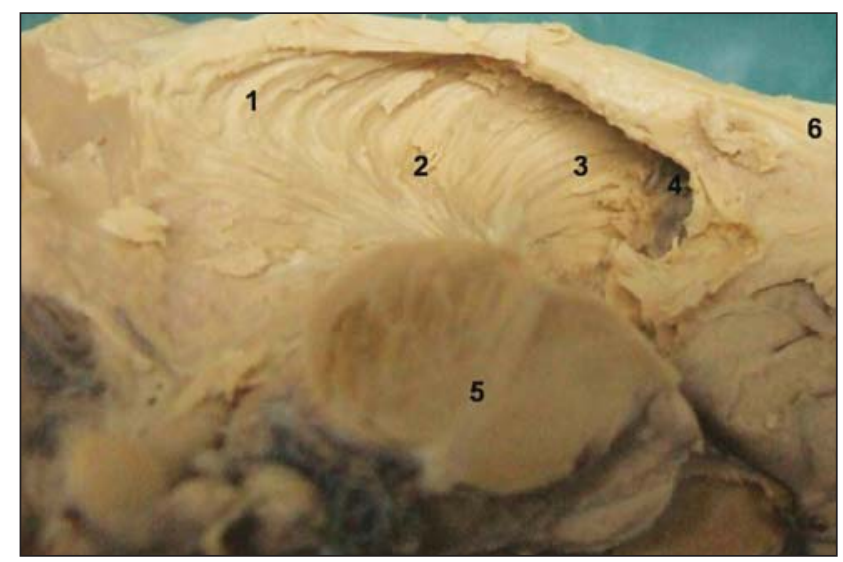

Figure 8: Exposure of left internal capsule through the roof of temporal horn of lateral ventricle (Retro and sublentiform part of internal capsule that form optic radiation). 1,2E3 retro and sublenticular part of internal capsule, 4-temporal horn of lateral ventricle, 5-midbrain,6-optic radiation (seen on lateral surface).

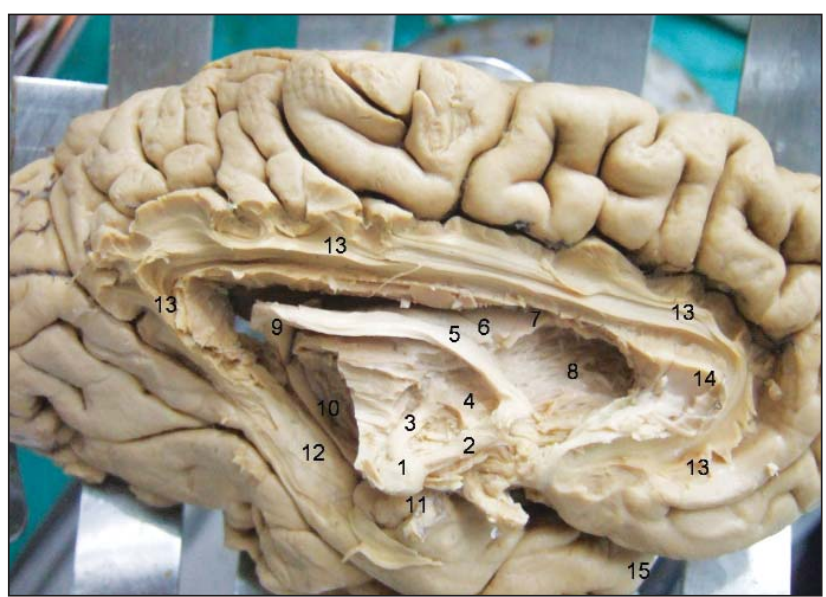

Figure 9: Exposure of left internal capsule from medial cerebral surface (Partial dissection). Part of caudate nucleus removed and medial surface of anterior limb of internal capsule (anterior thalamic radiation) is seen. In dissection various parts of Papez circuit is also seen after removal of brain stem, cerebellum and part of thalamus and caudate nucleus-1. Mamillary body, 2. post commissural fornix, 3. mamillothalamic tract, 4. anteror thalamic nuclei, 5. body of fornix, 6. stria terminalis, 7.caudate nucleus,8. anterior thalamic radiation, 9. crus fornix, 10. fimbria fornix, 11. uncus, 12. parahippocampal gyrus, 13.cingulum, 14. rostrum of corpus callosum,15.temporal pole. 


\section{RESULTS}

The projection fibers that form the internal capsule arising from almost all parts of cerebral cortex pass downwards. Above the level of upper border of the lentiform nucleus, these fibers are arranged in a radiating pattern, hence called the corona radiata (Figures 2,4,5). The corona continues caudally as the internal capsule, where these fibers are densely packed. The fibers of the internal capsule are arranged more densely to continue below as the crus cerebri (cerebral peduncle). The internal capsule is bounded laterally by the lentiform nucleus and medially by the caudate nucleus and the thalamus. The head of the caudate nucleus is in contact with the medial surface of the anterior limb of the internal capsule. The body of the caudate nucleus is in relation with the upper part medial surface of the posterior internal capsule where the thalamus is in contact with the lower part. A portion of the medial surface of genu between the interval of thalamus and caudate nucleus is subependymal and this portion is just lateral to the foramen of Monro, separated only by ependymal layer and ventricle. The internal capsule has five parts; anterior limb, posterior limb, genu, retrolenticular and sublenticular parts. The anterior and posterior limb of internal capsule join at a right angle around the medial margin of apex of the pallidal part of the lentiform nucleus to form the genu. The anterior limb is located between the caudate nucleus medially and the lentiform nucleus laterally and a posterior limb interposed between the thalamus medially and the lentiform nucleus laterally. The anterior limb is composed predominantly of fibers that connect the anterior and medial thalamus (anterior thalamic radiation) to the frontal lobe (Figure 9) along with fronto-pontine fibers. The genu of the internal capsule, contains important corticobulbar fibers that originate from the inferior part of primary motor area to the motor nuclei of the cranial nerves along with the superior thalamic radiation. In addition to the posterior thalamic radiation to the cortex, the posterior limb contains the corticospinal fibers to the motor nuclei of the upper and lower extremity and trunk, corticorubral and cortico-pontine fibers. The fibers of the internal capsule that curve around the posterior edge of the lentiform nucleus are called the retrolenticular fibers. The fibers that pass below the lentiform nucleus and are referred to as sublenticular fibers.
The sublenticular part contains the auditory radiation fibers directed from the medial geniculate body to the auditory area. The retrolenticular part and rest of the sublentiform part form the optic radiation that course from the lateral geniculate to the walls of the calcarine sulcus. Some optic radiation fibers also pass in the retrolenticular part of the internal capsule but most pass through the sublenticular part. The optic radiations are separated from the roof and lateral wall of the temporal horn and the lateral atrial wall by only a thin layer of tapetal fibers (Figure 8) along with some associational, commisural and other projection fibers.

The fibers passing to the superior lip of the calcarine fissure leave the upper part of the lateral geniculate body and course almost directly posterior around the lateral aspect of the atrium to reach the striate visual cortex. Fibers from the lower part of the geniculate body destined for the inferior lip of the calcarine fissure initially loop forward and downward in the temporal lobe forming Meyer's loop before turning back to join the other fibers in the optic radiations.

In our study we dissected out different parts of the Papez circuit during dissection. The parts of the circuit are (sequentially) Hippocampus-Fornix-Mammillary body-Mammillothalamic tract-Anterior group of thalamic nucleus-Anterior thalamic projection to cingulate gyrus-Cingulum-Parahippocampus-Dentate gyrus-Hippocampus.

Hippocampus (Figures 5-8): It is thought to be the center (nucleus) of the Papez circuit. The circuit starts and ends here. It is situated in the floor of the temporal horn. In the floor of the temporal horn, lateral to it is collateral eminence. Anterior to the head of the hippocampus is the amagdala. It is separated medially from the thalamus by the choroidal fissure and choroids plexus of temporal horn. It has head, body and tail (From anterior to posterior). Tail is continues as fimbria of fornix posteriorly. The hippocampus is connected with septal area, hypothalamus and thalamus of the same side by foniceal fibers and by commissural fibers to opposite side. It is also connected with parahippocampal gyrus and cingulated gyrus through dentate gyrus. Hippocampus, sabiculum and dentate gyrus together called hippocampal formation. 
Fornix (Figures 1-8): The fornix consists mainly of hippocampomamillary and hippocamposeptal fibers. Forniceal white fibers arise from the hippocampus, subiculum, and dentate gyrus. It wraps the thalamus in the wall of lateral ventricle. The fornix is $C$ shaped. It has four parts: fimbria, crus, body, and columns of fornix.

Fimbria started from tail of hippocampus and forms the posterior medial part of floor of temporal horn. The fimbriodentate sulcus separates it from dentate gyrus. It is separated from the geniculate body, optic and auditory radiations by the choroidal fissure.

The crus of the fornix is the posterior continuation of fimbria that covers the posterior surface of the pulvinar in the medial part of the atrium and arches superio-medially toward the lower surface of the splenium. It forms the medial part of anterior wall of atrium. A thin sheet of white fiber that interconnects the medial edge of both crus below the splenium is known as the hippocampal commissure.

The body of the fornix is formed by the meeting of both crus in midline at the junction of the body and atrium of the lateral ventricle. Passing forward above the thalami superiorly it blends with lower edge of the septum pellucidum and forms the medial wall of the body of the lateral ventricle.

The column of fornix begins when the body of fornix separates into a pair of column at the anterior pole of the thalamus. The columns arches anteriorinferiorly to form the superior and anterior margins of the foramen of Monro. It then blends into the lateral walls of the third ventricle and passes down behind the anterior commissure through the hypothalamus to mammilary body.

The part of the thalamus lateral to the body of the fornix forms the floor of the body of the lateral ventricle and the part medial to the fornix forms part of the lateral wall of the velum interpositum and third ventricle. The crus of the fornix crosses the pulvinar approximately midway between the medial and lateral edge of the pulvinar. The part of the pulvinar lateral to the crus of the fornix forms part of the anterior wall of the atrium. The lower border of the fornix forms the upper border of the choroidal fissure and lower border of choroid fissure is formed by stria medullaris; choroidal plexus is attached here. The septum pellucidum stretches across the interval between the anterior parts of the corpus callosum and the body of the fornix. It is composed of paired laminae and separates the frontal horns and bodies of lateral ventricles.

Mamillary body and mamillothalamic tract (Figures 1-4): Mamillary bodies are egg-shaped paired structures in the floor of third ventricle situated on the both side of midline behind the pituitary stalk and can easily be seen both from the ventricular surface and inferior surface of brain. The column of fornix ends and the mamillothalamic tract originates from here. The mamillothalamic tract ascends superio-laterally and posteriorly through the thalamus to anterior group of nucleus. Some fibers of the tract also go to dorso-medial nucleus of thalamus.

Anterior group of thalamic nuclei (Figures 2-4): Anterior thalamic group of nuclei lies anteriorly near the foramen of Monro. They receive mamillothalamic tract and project anterior thalamic radiation.

Anterior thalamic projection (Figures 2-4): Fibers from anterior group of thalamic nucleus projected anteriorly and anterior-superiorly that passed lateral to head of caudate nucleus and joins to anterior limb of internal capsule. These fibers curve superio-medially and pass through the fibers of corpus callosum to end in anterior part of cingulate gyrus. Some fiber of the anterior thalamic projection seen to end in head of caudate nucleus and some fiber seen to be passed through the lateral part of caudate nucleus. Small portion of this radiation also passed to prefrontal cortex.

Cingulate gyrus (Figures 1-4): It is on the medial cerebral surface, just above the corpus callosum. It begins anterior to rostrum of corpus callosum and septal area. It follows the curvature of callosum, below \& behind the splenium it continues with parahippocampal gyrus through isthmus. Anteriorly it receives anterior thalamic radiation. The cingulum within the cingulate gyrus contains long and short association fibers that follow the curve of the cingulate gyrus and corpus callosum. Cingulum ends in parahippocampal gyrus.

Parahippocampal gyrus (Figures 3,4,6,7,8): It is the most medial gyrus on the inferior surface of temporal lobe. It receives cingulum and projects to hippocampus through the dentate gyrus. 
Dentate gyrus (Figures 6,7,8): It is a short narrow gyrus can only be seen to adequate lateral retraction of parahippocampal gyrus by its characteristic appearance. It connects parahippocampal gyrus to hippocampus.

\section{DISCUSSION}

Dissection following fibers tracts of the white matter of the brain, to illustrate the internal structures, was the first technique that allowed a true appreciation of the three dimensional features of the brain (16). The internal capsule, other white fibers and ventricular system may be affected by various pathologies, such as degenerative, demyelinating, deficiency condition (vitamin deficiency), vascular (infarction, haemorrhage, AVM, angioma), hypoxia, intrinsic neoplastic (glioma, oligodendroglioma, ganglioglioma, primitive neuroectodermal tumour, metastatic lesion), infection (tuberculosis, pyogenic abscess), parasitic involvement (neurocystocercosis, hydatid cyst), trauma , iatrogenic (postsurgical), epilepsy, psychiatric illness etc. Sometime intraventricular lesions such as ependymoma, glioma, meningioma, colloid cyst, craniopharyngioma, choroids plexus papilloma, metastatic etc can extend into internal capsule and other white fibers tract. Proper microneurosurgical 3-dimensional anatomical knowledge and orientation is the essential thing along with physiological, pathological and microneurosurgical skill for dealing of above mentioned pathologies.

In 1937 James Papez described a pathway involving some limbic and cortical structures and associated pathways. (12) The pathway forms a series of connections, which has since been called the Papez circuit or medial limbic circuit. $(6,15,22)$

The circuit may be affected by various pathologies, such as neurodegenerative diseases (Alzheimer's disease), (22) metabolite deficiencies (VitaminB1 deficiency, Korsakoff psychosis),(4) vascular disease (infarction, AVM, Angioma), hypoxia (temporal mesial sclerosis), $(3,7)$ neoplastic diseases (intrinsic to Papez circuit-glioma, extrinsic to the circuit-glioma, meningioma, colloid cyst, craniopharyngioma, choroids plexus papilloma, and other tumors), trauma, iatrogenic (postsurgical),epilepsy, psychiatric illness (15) etc. These patients may present with defective functions of Papez circuit such as memory disturbance (specially recent), personality changes, changes in emotional behavior, loss of spontaneity and initiative, affective disorders, hallucinations, and intractable epilepsy with or without features of intracranial space occupying lesion (2). Various investigations including neuroimaging can identify these conditions with ease.

Surgical intervention is needed in neoplastic, vascular, intractable epileptic and intractable psychiatric conditions. Appropriate surgical approach and per-operative identification and preservation of Papez circuit along with other related vital structures are essential for a good outcome in these surgeries. Lesion making surgeries in psychiatric illness should be done only in definite indication with extreme caution (15). In case of intractable epilepsy where mesial temporal excision is planned, the opposite mesial temporal lobe's function should be intact, otherwise postoperatively the patient may become disastrously disabled like patient H.M (22).

White fiber dissection is not a new thing. Many early neuro-anatomists demonstrated tracts and fascicles of brain by white fiber dissection, though modern technique of fiber dissection was not used $(1,5,13,16,17)$. In fact, the fiber dissection technique was one of the first methods used to demonstrate the internal structures of the brain (16). In 1927, English anatomist Herbert Mayo demonstrated corona radiata, internal capsule, superior and inferior cerebellar peduncles, fasciculus uncinatus, fasciculus longitudinalis superior, outer surface of lentiform nucleus, tapetum, mamillothalamic tract and anterior commissure (16). Because the fiber dissection technique is complicated and time consuming, its neglect is almost inevitable after the development of the microtome and histological techniques (16). In the early part of the 20th the century, only a few anatomists preferred to study the anatomic features of the brain (16). An extensive historical review is beyond the scope of this paper and was made in an outstanding manner by Ture et al (16). Joseph Klingler (1888-1963) was an anatomist in Basel that made the greatest contribution to the fiber dissection technique. In 1935, he developed an improved method of brain fixation and a technique that now bears his name $(10,11)$ (Klingler's technique). Like others, he dissected formalin-fixed brains with wooden spatulas. However, he froze and 
thawed the brains before dissection. Freezing helps to separate the fibers. His superb atlas containing detailed anatomic studies of the brain was published in 1956. Although his studies were impressive, this technique never became widely used $(10,11,16)$. While the freezing method is an aid to dissection and generally increases the distinction between the grey and white matter of the brain, it does not produce absolutely consistent results, as Klingler himself acknowledged (10).

Illustrations of the internal structures of the brain in current textbooks are usually pictures of sections or schematic drawings. Only few fiber dissections from earlier textbooks are still reproduced (16). In Rhoton's masterpiece which was published in 2002, we can appreciate some superb pictures of the white matter anatomy. In this publication he described the white matter anatomy in detail.

The evolution of neuroimaging techniques has imposed a greater demand of knowledge. Without the knowing of the 3-dimensional internal anatomy of the brain one can not interpret precisely the new neuroimaging studies such as "tractography", diffusion tensor imaging (DTI). Diffusion-tensor magnetic resonance(MR) imaging is a promising and rapidly evolving tool to evaluate white matter anatomy. The first attempt to visualize the white matter tract was made by Kinosada et al. in 1993 (9). In the literature, one can find reports about the correlation of arteriovenous malformations (AVM) (18) or tumors (8) with the white matter tracts and ventricles. According with Ture et al (16) the fiber dissection technique is a demanding and timeconsuming technique. The technique was somehow abandoned after the introduction of the microtome and histological preparations. The histological sections are very important to the interpretation of biplanar Magnetic Resonance Imaging (MRI) films, but to build our ability to think in three dimensions, the knowledge of intrinsic white matter anatomy is of great importance. The combination of histological techniques with fiber dissection technique improves the understanding and prevents misinterpretation of the complex anatomic features of structures. The first surgeon that gave attention to this technique was Yasargil (20).After he gained knowledge with this technique, he applied it to all of his routine microsurgical procedures $(19,20,21)$.

\section{CONCLUSION}

The white fiber dissection is the best method to learn the 3-dimensional internal anatomy of brain. Knowledge of the microsurgical anatomy of the internal capsule and other white fibers tracts is not only important for understanding the three dimensional intrinsic brain anatomy but also important in the management of intrinsic brain lesion such as glioma, vascular malformations etc. It is especially very important for the younger generation of neurosurgeons to become experts and experience in microsurgical 3-dimensional neuroanatomic features for application in microsurgical practice.

\section{ACKNOWLEDGMENTS}

The authors would like to express the deep appreciation to Prof. Dr. Atul Goel., who placed his laboratory facilities at principle author's disposal. He stimulated the technique and introduced the fiber dissection technique in his Microneurosurgical fellowship Course at King Edward Hospital, Parel, Mumbai, India.

\section{REFERENCES}

1. Bell C: The anatomy of the brain. London: Longman and Co; 1802

2. Catherine Haberland: Basics of neuropathology. In: Craig Percy ed. Clinical Neuropathology: Text and Color Atlas., New York, Demos Medical Publishing, 2007: 25

3. Catherine Haberland: Cerebral hypoxia. In: Craig Percy ed. Clinical Neuropathology: Text and Color Atlas. New York, Demos Medical Publishing, 2007: 32-41

4. Catherine Haberland: Acquired neurometabolic disease. In: Craig Percy ed. Clinical Neuropathology: Text and Color Atlas. New York, Demos Medical Publishing, 2007: 199-202

5. Foville ALF. Traité complet de l'anatomie, de la physiologie et de la pathologie du système nerveux cérébrospinal. Paris: Fortin, Masson et Cie, 1844

6. Goldenberg PL: Functional neurosurgery, In: Schmidek HH, Sweet WH eds. Operative Neurosurgical Techniques: Indications, Methods and Results, ed 2. Vol 2, Orlando: Grune \& Stratton, 1988:1035-1068

7. Hogan, R. E: Mesial temporal sclerosis clinicopathological correlations. Arch Neurol 58, 1484-1486, 2001

8. Holodny AI, Schwartz TH, Ollenschleger M, Liu WC, Schulder M: Tumor involvement of the corticospinal tract: Diffusion magnetic resonance tractography with intraoperative correlation. J Neurosurg 95:1082, 2001

9. Kinosada $Y$, Ono M, Okuda $Y$, Seta H, Hada $Y$, Hattori T, Nomura Y, Sakuma H, Takeda K, Ishii Y: MR tractography: Visualization of structure of nerve fiber system from diffusion weighted images with maximum intensity projection method. Nippon Igaku Hoshasen Gakkai Zasshi 53:171-179, 1993 
10. Klingler J: Erleichterung der makroskopischen Praeparation des Gehirns durch den Gefrierprozess. Schweiz Arch Neurol Psychiatr 36:247-256, 1935

11. Klingler J, Gloor P: The connections of the amygdala and of the anterior temporal cortex in the human brain. J Comp Neurol 115:333-369, 1960

12. Papez JW: A proposed mechanism of emotion. Arch Neurol Psychiatry 38:725-743, 1937

13. Reil JC: Fragmente über die Bildung des kleinen Gehirns im Menschen. Arch Physiol Halle 8:1-58,1807-1808

14. Rhoton, AL Jr: The supratentorial cranial space: microsurgical Anatomy and surgical approaches: Chapter 1 . The Cerebrum. Neurosurgery 51:(Suppl):1-52, 2002

15. Feldman RP, Alterman RL, Goodrich JT: Contemporary psychosurgery and a look to the future.J Neurosurg 95:944-956, 2001

16. Ture U, Yasargil MG, Friedman AH, Al-Mefty O: Fiber dissection technique: Lateral aspect of the brain. Neurosurgery 47:417-426, 2000
17. Vieussens R: Neurographia universalis. Lyons: Lugduni, Apud Joannem Certe, 1685

18. Yamada K, Kizu O, Ito H, Nishimura T: Tractography for an arteriovenous malformation. Neurology 24:62-69,2004

19. Yasargil MG: Microneurosurgery vol III A: AVM of the brain history, embryology, pathological considerations, hemodynamics, diagnostic studies, microsurgical anatomy. Stuttgart: Georg Thieme,1987

20. Yasargil MG: Microneurosurgery vol IV A: CNS tumorssurgical anatomy, neuropathology, neuroradiology, neurophisiology, clinical considerations, operability, treatment options. Stuttgart: Georg Thieme, 1994

21. Yasargil MG: Microneurosurgery vol I Microsurgical anatomy of the basal cisterns and vessels of the brain .Stuttgart: Georg Thieme,1984

22. Hendelmann WJ: The limbic system. In: Atlas of Functional Neuroanatomy, 2 ed. New York: Taylor and Francis Group, LLC, 2006: 202-228 